\title{
9. THE ENHANCEMENT OF ETHICAL THINKING
}

This book has considered the place of ethics in the curriculum and the contribution that can be made to students' thinking that potentially will contribute to a broadening of scientific and technological literacy. Although there is debate about the place of ethics in the curriculum we hope that this book has contributed to that debate and moved it on. While we have argued that ethics, and in particular bioethics, is a small part of the curriculum, nevertheless we consider it to be an important part and one that needs to be done well.

The introduction of ethics is already seen by students as an important part of their education and connects school science and technology with the worlds in which they live. It has the potential to connect directly with their concerns and the issues that they consider important. The introduction of ethics, rather than being another area of content to be 'learnt', can also be used as a framework to enhance students' thinking skills. In developing ideas about, and approaches to, ethical thinking an important aspect then is to develop conceptual frameworks of how students make progress in ethical thinking. Rather than progression being absolute or fixed, it is probably more useful to develop ideas about the characteristics of ethical thinking and develop strategies to assist students to make progress with these characteristics in mind. These characteristics were highlighted in chapter 2 and provided a framework for the rest of book.

Making the ethics component relate to relevant work and real issues seems to help engage students in the learning, and should aim to provide opportunities for heightening ethical sensitivity, increasing ethical knowledge, and improving deliberation and justification skills. It should extend students' ability to analyse key concepts and principles, integrate the appropriate scientific and technological knowledge, as well as provide for the enhancement of critical thinking, argumentation skills, and sensitivity to the rights and views of others.

An essential premise of our work has been that ethical thinking must engage with the relevant knowledge base, for example science, technology, socio-science. A key feature for successful implementation centres on teacher knowledge in both the planning and the implementation of appropriate authentic classroom experiences. The teacher needs to be able to integrate knowledge of the issue or topic with knowledge of ethical reasoning approaches. Teachers need to teach their students explicitly about ethical principles and a decision-making process. Consideration must also be given to appropriate classroom practice, including knowledge of the curriculum, knowledge of specific teaching and assessment strategies that enable students to develop and extend their own knowledge and understanding, as well as 
knowledge of the students. The teacher's role is one of assisting students to recognise pluralism, and distinguish between sound and unsound ethical reasoning, between facts and opinions, and between strong and weak scientific evidence.

The classroom environment developed by the teacher is crucial in enabling students to express and explore often diverse views in a safe and supportive manner. Teacher planning for discussion has emerged as an essential part of that process. It is important that teachers model ethical behaviour themselves as well as modelling argumentation skills by providing evidence, making explicit underlying assumptions and identifying exceptions. It is acknowledged that student engagement in critical analysis and argumentation is more to do with how a teacher organises the classroom activity than the characteristics of the students or groups. The introduction of ethics adds to the requisite knowledge required by teachers but does result in enhanced thinking, greater learning and the application of science and technology ideas to the world of the student. Bioethics has been shown to be successfully introduced to younger students and this book proposes that repeated exposure to bioethics may increase the likelihood that all students, regardless of their ethical maturity, will have enhanced opportunities to learn about bioethics. A narrative approach to ethics, which foregrounds the implications of cultural diversity and the significance and value of individual experiences is potentially inclusive in explicit ways of all young people in classrooms.

All this highlights that teacher professional learning is crucial if ethical thinking, and in this case bioethics, is introduced into teaching and learning in science and technology education. An effective process of professional learning, as this research has highlighted, takes time and resource.

\section{CONCLUDING COMMENT}

This book, the result of an international collaborative study, has shown that ethics, in particular bioethics, can be introduced effectively into the classroom throughout schooling. Both teachers and students who contributed to our research findings, developing ethical thinking in the process, found the exercise to be a rewarding experience that has enhanced their learning, both about bioethics and about science and technology. Moreover, this book also indicates that this is a fruitful area of research and development for the future.

Alister Jones and Anne McKim

School of Education,

University of Waikato

Michael Reiss

Institute of Education,

University of London 